\title{
Enzymes and genes of taurine and isethionate dissimilation in Paracoccus denitrificans
}

\author{
Chantal Brüggemann, $†$ Karin Denger, Alasdair M. Cook and Jürgen Ruff \\ Department of Biology, The University, D-78457 Konstanz, Germany
}

Correspondence

Alasdair Cook

alasdair.cook@uni-konstanz.de

\begin{abstract}
Growth of the $\alpha$-proteobacterium Paracoccus denitrificans NKNIS with taurine or isethionate as sole source of carbon involves sulfoacetaldehyde acetyltransferase (Xsc), which is presumably encoded by an $x S c$ gene in subgroup 3 , none of whose gene products has been characterized. The genome of the $\alpha$-proteobacterium Rhodobacter sphaeroides 2.4.1 was interpreted to contain a nine-gene cluster encoding the inducible dissimilation of taurine, and this deduced pathway included a regulator, a tripartite ATP-independent transporter, taurine dehydrogenase (TDH; presumably TauXY) as well as Xsc (subgroup 3), a hypothetical protein and phosphate acetyltransferase (Pta). A similar cluster was found in $P$. denitrificans NKNIS, in contrast to an analogous cluster encoding an ATP-binding cassette transporter in Paracoccus pantotrophus. Inducible TDH, Xsc and Pta were found in extracts of taurine-grown cells of strain NKNIS. TDH oxidized taurine to sulfoacetaldehyde and ammonium ion with cytochrome $c$ as electron acceptor. Whereas Xsc and Pta were soluble enzymes, TDH was located in the particulate fraction, where inducible proteins with the expected masses of TauXY (14 and $50 \mathrm{kDa}$, respectively) were detected by SDS-PAGE. Xsc and Pta were separated by anion-exchange chromatography. Xsc was effectively pure; the molecular mass of the subunit $(64 \mathrm{kDa})$ and the $\mathrm{N}$-terminal amino acid sequence confirmed the identification of the $x s c$ gene. Inducible isethionate dehydrogenase (IDH), Xsc and Pta were assayed in extracts of isethionate-grown cells of strain NKNIS. IDH was located in the particulate fraction, oxidized isethionate to sulfoacetaldehyde with cytochrome $c$ as electron acceptor and correlated with the expression of a $62 \mathrm{kDa}$ protein. Strain NKNIS excreted sulfite and sulfate during growth with a sulfonate and no sulfite dehydrogenase was detected. There is considerable biochemical, genetic and regulatory complexity in the degradation of these simple molecules.
\end{abstract}

\section{INTRODUCTION}

Taurine (2-aminoethanesulfonate) (Fig. 1a) and isethionate (2-hydroxyethanesulfonate) are widespread natural products whose utilization as sulfur or as carbon and energy

†Present address: Institut fur Biologie der Freien Universitat Berlin, D-14195 Berlin, Germany.

Abbreviations: ABC transporter, ATP-binding cassette transporter; DCPIP, dichlorophenol indophenol; IDH, isethionate dehydrogenase; MALDI-TOF-MS, matrix-assisted, laser-desorption ionization time-offlight mass spectrometry; Pta, phosphate acetyltransferase; TDH, taurine dehydrogenase; ThDP, thiamin diphosphate; Tpa, taurine: pyruvate aminotransferase; TRAP transporter, tripartite ATP-independent transporter; Xsc, sulfoacetaldehyde acetyltransferase.

The GenBank accession numbers for the sequences reported in this paper are AY498613 (gene cluster in Paracoccus denitrificans NKNIS), AY498615 (gene cluster in Paracoccus pantotrophus NKNCYSA), AY498614 (gene cluster in P. pantotrophus DSM 65), AY498616 (partial tauY in Achromobacter xylosoxidans NCIMB 10751), AY498617 (partial tauY in Comamonas sp. strain SFCD1) and AY498618 (partial tauY in Ralstonia sp. strain EDS1). sources for growth has been recognized for many decades, though these phenomena have only recently been explored at the molecular level (Huxtable, 1992; Lie et al., 1998; Kertesz, 2000; Cook \& Denger, 2002). Transport of sulfonates into the cell is axiomatic, but little information is available on transport in dissimilatory pathways (Kertesz, 2001; Cook \& Denger, 2002), though an ABC (ATP-binding cassette) transporter (e.g. Ehrmann et al., 1998) has been postulated for taurine in Sinorhizobium meliloti (Ruff et al., 2003). The dissimilatory pathways, which are usually inducible, converge at sulfoacetaldehyde (Cook \& Denger, 2002) (Fig. 1a). A taurine:pyruvate transaminase (Tpa) (EC 2.6.1.77) (Laue \& Cook, 2000) is widespread, whereas a taurine dehydrogenase (TDH) (EC 1.4.99.2) (Fellman et al., 1980; Kondo \& Ishimoto, 1987) was thought to be rare (Cook \& Denger, 2002) until a gene(s) for TDH was hypothesized in the genome sequence of Sin. meliloti (Ruff et al., 2003) (Fig. 1b). The enzymic conversion of isethionate to sulfoacetaldehyde has been detected (Kondo et al., 1977) as has the metabolism of isethionate via 
desulfonation of sulfoacetaldehyde (King et al., 1997). This desulfonation, catalysed by the thiamin diphosphate (ThDP)-coupled sulfoacetaldehyde acetyltransferase (Xsc) (EC 2.3.3.15), yields acetyl phosphate, which is converted by phosphate acetyltransferase (Pta) (EC 2.3.1.8) into acetyl CoA for the Krebs and glyoxylate cycles in, for example, aerobic metabolism (Cook \& Denger, 2002; Ruff et al., 2003) (Fig. 1a).
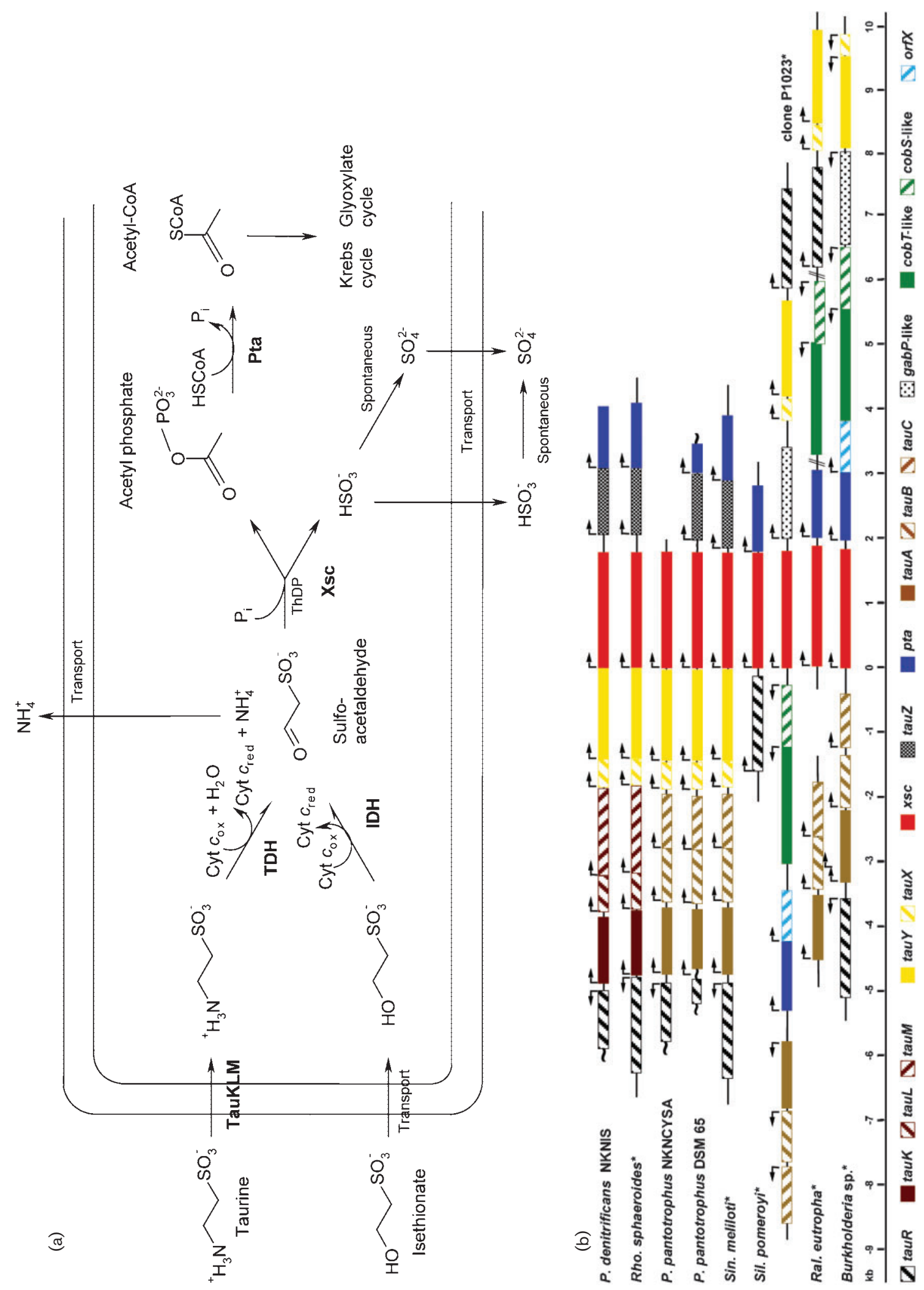
The established and putative xsc genes can be attributed to three subgroups, 1-3 (Denger et al., 2001; Ruff et al., 2003). Representative gene products of subgroups 1 and 2 have been characterized and confirmed to be encoded by the appropriate gene. All genes in subgroup 3 are found in $\alpha$-Proteobacteria (Ruff et al., 2003) and they are known in silico only, so the function of the gene product has not been confirmed.

We postulated that one genomic locus (SMb21525-SMb21532) encodes enzymes involved in the inducible degradation of taurine, the only sulfonate known to be degraded by Sin. meliloti Rm1021 (Fig. 1b) (Ruff et al., 2003), a member of the Rhizobiaceae in the $\alpha$-Proteobacteria. A similar pathway involving a TRAP transporter (tripartite ATP-independent periplasmic transporters were reviewed recently by Kelly \& Thomas, 2001) can be derived from genomic data from Rhodobacter sphaeroides 2.4.1, a member of the Rhodobacteraceae, in the $\alpha$-Proteobacteria (see below). Three other Rhodobacteraceae are known to dissimilate at least one sulfonate, Paracoccus denitrificans NKNIS (isethionate and taurine) and Paracoccus pantotrophus strains NKNCYSA (isethionate, sulfoacetate and taurine are relevant here) and DSM 65 (taurine) (Denger et al., 1997; Mikosch et al., 1999; Ruff et al., 2003). The initial work with the latter organisms was done under conditions of nitrate respiration, but it has since been observed that each organism dissimilates its sulfonate substrate(s) with oxygen as the terminal electron acceptor (K. Denger, unpublished). When several pathways of desulfonation of $\mathrm{C}_{2}$-sulfonates are present in one organism, Xsc seems to be induced in each case, but the convergent pathways are induced individually (Denger \& Cook, 2001). Furthermore, the reactive sulfite ion, which is released by Xsc (or other enzymes), is sometimes actively detoxified by sulfite dehydrogenase, as has been detected in Burkholderia sp. strain ICD (King et al., 1997; see also Reichenbecher et al., 1999) and in P. pantotrophus NKNCYSA (Rein, 1999), but sulfite is sometimes found transiently in large amounts outwith the cell (e.g. Thurnheer et al., 1986). Little is known about bacterial sulfite dehydrogenases (EC 1.8.2.1) [or sulfite oxidases (EC 1.8.3.1)] (Kappler \& Dahl, 2001).

This report shows the development of a hypothesis on the nature of the locus encoding an inducible pathway of taurine dissimilation in Rho. sphaeroides whose genes show high levels of similarity with a gene cluster found in P. denitrificans NKNIS. An analogous cluster in $P$. pantotrophus NKNCYSA (and DSM 65) presumably encodes an ABC transporter in place of the TRAP transporter. Inducible TDH, Xsc and Pta were detected in strain NKNIS and the reaction products were identified. The enzymes were subject to partial or complete purification and characterization; as predicted, Xsc was encoded by the $x s c$ gene. A separately induced isethionate dehydrogenase (IDH) was detected in P. denitrificans.

\section{METHODS}

Materials. The preparation of sulfoacetaldehyde, as the bisulfite addition complex, has been described previously (Denger et al., 2001). Commercial chemicals were of the highest purity available and were purchased from Fluka, Merck, Roth, Serva or Sigma. Native proteins were separated on a Mono Q column $(10 \times 10 \mathrm{~mm})$ (Pharmacia).

Organisms, growth, harvesting of cells and preparation of cell-free extracts. $P$. denitrificans NKNIS (DSM 15418), P. panto trophus NKNCYSA (DSM 12449), Ralstonia sp. strain EDS1 (DSM 13640) and Alcaligenes defragrans NKNTAU (DSM 11046) were iso lated in this laboratory (Denger et al., 1997; Mikosch et al., 1999; Denger \& Cook, 2001; Ruff et al., 2003). P. pantotrophus DSM 65 and Ralstonia eutropha JMP134 (DSM 4058) were obtained from the DSM Culture Collection (DSMZ, Braunschweig, Germany). Achro mobacter xylosoxidans NCIMB 10751 (Kondo et al., 1971) is avail able from NCIMB, Aberdeen. Comamonas sp. strain SFCD1 (King \& Quinn, 1997) (DSM 15091) was provided by J. Quinn, University of Belfast. Sin. meliloti Rm1021 was provided by Stefan Weidner, University of Bielefeld, Germany. Burkholderia sp. strain LB400 was obtained from J. Tiedje, Michigan State University, USA. Cells were grown aerobically at $30^{\circ} \mathrm{C}$ in mineral salts medium (Thurnheer et al., 1986) with $1020 \mathrm{mM}$ taurine, isethionate or acetate as the sole added source of carbon and energy for growth, unless otherwise stated. On occasion, the ammonium ion was omitted and taurine served as sole source of carbon and nitrogen for growth. Precultures $(3 \mathrm{ml})$ were grown in $30 \mathrm{ml}$ screw cap tubes in a roller. Growth experiments were done on the $100 \mathrm{ml}$ scale in $500 \mathrm{ml}$ Erlenmeyer flasks shaken in a water bath. Samples were taken at intervals to measure $\mathrm{OD}_{580}$, to assay protein and to determine the concentra tions of sulfate, sulfite, carbon source and, on occasion, ammonium ion. Similar cultures were used to generate small amounts of cells for enzyme assays. When large amounts of cells were needed, strain NKNIS was grown in a 41 fermenter with 3.51 working volume in $20 \mathrm{mM}$ taurine (or isethionate or acetate) salts medium, harvested at $\mathrm{OD}_{580}=0 \cdot 8 \quad 0 \cdot 9\left(300 \mathrm{mg}\right.$ protein $\left.\mathrm{l}^{1}\right)$ by centrifugation $(15000 \mathrm{~g}$, $20 \mathrm{~min}, 4^{\circ} \mathrm{C}$ ), washed in $50 \mathrm{mM}$ potassium phosphate buffer, $\mathrm{pH} 7 \cdot 5$ (containing $2.5 \mathrm{mM} \mathrm{MgCl}_{2}$ ), and stored frozen. The same

Fig. 1. The degradative pathways for taurine and isethionate in $P$. denitrificans NKNIS (a) and the genetic organization of corresponding genes in selected $\alpha$ - and $\beta$-Proteobacteria (b). The reannotated cluster (SMb21525-SMb21532; line 5) presumably encoding degradation of taurine in Sin. meliloti Rm1021 comprises genes encoding a potential regulator (TauR), an ABC transporter, putative TDH (TauXY), Xsc, unknown function (TauZ) and Pta (Ruff et al., 2003). The gene cluster in the Rho. sphaeroides 2.4.1 genome (Rsph2616-2608; line 2) presumably encodes TauR, a TRAP transporter (TauKLM), TDH, Xsc, TauZ and Pta (see Table 1). The cluster in P. denitrificans NKNIS (line 1) resembles that in Rho. sphaeroides (line 2) (Table 1), whereas the cluster in $P$. pantotrophus (lines 3,4) resembles that in Sin. meliloti (line 5). The incomplete genome sequence of the $\alpha$-proteobacterium Sil. pomeroyi DSS-3 (line 6) contains adjacent tauR-, xsc- and pta-like genes. The gene cluster around $x S c$ in Burkholderia sp. strain LB400 (line 9), data from the L. major genome project (clone P1023) (line 7), and, to a lesser extent, data from Ral. eutropha JMP134 (line 8), indicate the relatively close proximity of tauXY and $x S C$, together with regulation, transport and the cobST and orfX (relevance unknown) genes. Key: arrows, direction of transcription; $\sim$, incomplete sequence; *, data from genome sequencing project. 
buffer served as extraction buffer. Cell free extracts free of nucleic acids were generated after disruption by three passages through a chilled French press set at $138 \mathrm{MPa}$ (Junker et al., 1994) and they could be stored for several weeks at $20{ }^{\circ} \mathrm{C}$ without significant loss of activity. The membrane/particulate fraction was obtained by ultracentrifugation $\left(170000 \mathrm{~g}, 30 \mathrm{~min}, 4^{\circ} \mathrm{C}\right)$. If the extract was required in a different buffer, $2.5 \mathrm{ml}$ portions were rebuffered with equilibrated PD 10 (Pharmacia) columns according to the manufac turer's instructions. Cells, which were to provide template DNA, were washed twice in water and frozen and thawed prior to use to make genomic DNA more available.

Enzyme assays. TDH was routinely assayed spectrophotometrically as the taurine dependent reduction of dichlorophenol indophenol (DCPIP) at $600 \mathrm{~nm}$ (molar extinction coefficient $16100 \mathrm{M}^{1} \mathrm{~cm}^{1}$; Jones, 1979). The reaction mixture contained (in a final volume of $1 \cdot 0 \mathrm{ml}$ ): $40 \mu \mathrm{mol}$ potassium phosphate buffer, $\mathrm{pH} 7 \cdot 2,25 \mu \mathrm{mol}$ taur ine, $100 \mathrm{nmol}$ DCPIP and $0 \cdot 1 \mathrm{mg}$ protein with which the reaction was started. The reaction was proportional to the protein content up to $2 \mathrm{mg} \mathrm{ml}{ }^{1}$ and was linear for at least $2 \mathrm{~min}$. The routine assay was occasionally augmented by following the disappearance of taurine and the formation of sulfoacetaldehyde. DCPIP and taurine tended to interfere with the routine determination of the other product of oxi dative deamination, ammonium ion, so lower amounts were used in the assay $(10 \mu \mathrm{mol}$ taurine, $50 \mathrm{nmol}$ DCPIP). DCPIP could be replaced with beef heart cytochrome $c(50 \mathrm{nmol})$, and the optimized photometric enzyme assay also contained $100 \mu \mathrm{mol}$ Tris/HCl buffer, $\mathrm{pH} 9 \cdot 0,25 \mu \mathrm{mol}$ taurine and $0 \cdot 010 \cdot 05 \mathrm{mg}$ protein with which the reaction was started: the wavelength used was $550 \mathrm{~nm}$ and the molar extinction coefficient was $21000 \mathrm{M}^{1} \mathrm{~cm}^{1}$ (Ensley et al., 1982).

IDH was routinely assayed spectrophotometrically as the isethionate dependent reduction of DCPIP at $600 \mathrm{~nm}$. The reaction mixture contained (in a final volume of $1.0 \mathrm{ml}$ ): $40 \mu \mathrm{mol}$ potassium phosphate buffer, $\mathrm{pH} 7 \cdot 2,25 \mu \mathrm{mol}$ isethionate, $100 \mathrm{nmol}$ DCPIP and $0 \cdot 11 \mathrm{mg}$ protein with which the reaction was started. The reaction was proportional to the protein content up to $2 \mathrm{mg} \mathrm{ml}^{1}$ and was linear for at least $2 \mathrm{~min}$. DCPIP could be replaced with beef heart cytochrome $c$ $(50 \mathrm{nmol})$

Xsc was assayed by GC as the ThDP and phosphate dependent release of acetate after acidification to hydrolyse the acetyl phosphate formed (Ruff et al., 2003). The routine assay was occasionally augmented by colorimetric determination of acetyl phosphate, by the disappearance of substrate or by the formation of sulfite (Ruff et al., 2003).

Pta was assayed photometrically as the HS CoA dependent formation of acetyl CoA (Bergmeyer et al., 1983).

Tpa was assayed discontinuously at $30^{\circ} \mathrm{C}$ as the pyruvate dependent disappearance of taurine concomitant with the formation of alanine. The reaction mixture contained (in a final volume of $1.0 \mathrm{ml}$ ): $40 \mu \mathrm{mol}$ Tris/ $\mathrm{HCl}, \mathrm{pH} 9 \cdot 0,5 \mu \mathrm{mol}$ taurine, $10 \mu \mathrm{mol}$ pyruvate, $100 \mathrm{nmol}$ pyridoxal 5 phosphate and $0 \cdot 11 \mathrm{mg}$ protein with which the reaction was started. Samples were taken at intervals, derivatized with Sanger's reagent, and subject to separation by HPLC (Laue et al., 1997).

Sulfite dehydrogenase was assayed spectrophotometrically with $\mathrm{K}_{3} \mathrm{Fe}(\mathrm{CN})_{6}$ or cytochrome $c$ as electron acceptor (Reichenbecher et al., 1999).

Cytochromes were assayed spectrophotometrically. Cell extracts of taurine or acetate grown cells were examined as redox difference spectra of dithionite reduced samples versus air oxidized samples. Cytochrome $c$ was considered to have an $M_{\mathrm{r}}$ value of 12000 and a molar absorption coefficient for the $\alpha$ band of $19.0 \mathrm{mM} \mathrm{cm}^{1}$ (Chance \& Williams, 1955).
Purification of Xsc and separation of Pta. Particulate matter was removed from crude extract by ultracentrifugation (see above) and the soluble fraction (the supernatant fluid) was diluted $1: 2 \cdot 5$ with distilled water to generate the correct buffer concentration for chromatography. This generated a precipitate, which was removed by centrifugation $(10000 \mathrm{~g}, 3 \mathrm{~min}$, room temperature). The clear supernatant fluid was loaded on to a Mono Q anion exchange column and protein was eluted as described elsewhere (Ruff et al., 2003). Representative fractions were assayed for Xsc, which was found to be essentially homogeneous, and for Pta.

Fractionation of TDH. The membrane fraction (e.g. $2 \cdot 0 \mathrm{ml}$ ) was

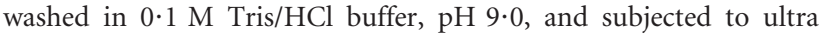
centrifugation (see above). The pellet was resuspended in the same volume of fresh buffer.

Analytical methods. Absorbance was measured in a Uvikon 922 spectrophotometer (Kontron). Sulfate was quantified as turbidity in the presence of $\mathrm{BaCl}_{2}$ (Sörbo, 1987). Sulfite was quantified as the fuchsin derivative as described elsewhere (Kondo et al., 1982; Thurnheer et al., 1986). Ammonium ion was routinely assayed colorimetrically by the Berthelot reaction (Gesellschalt Deutscher Chemiker, 1996) and occasionally confirmed enzymically in the specific reaction with glutamate dehydrogenase (Bergmeyer, 1983). Acetyl phosphate was determined chemically as iron(III) acetyl hydroxamate (Stadtman, 1957; Racker, 1962). Reverse phase HPLC was used to quantify taurine (Laue et al., 1997) or sulfoacetaldehyde (Cunningham et al., 1998) after derivatization. Acetate was quanti fied by GC (Laue et al., 1997). SDS PAGE and staining were done by standard methods (Laemmli, 1970) to monitor protein purifica tion and to estimate molecular masses under protein denaturing conditions. Values for the molecular mass of native proteins were assayed by gel filtration chromatography on a Superose 12 column as described previously (Ruff et al., 2003). The sequencing of the $\mathrm{N}$ terminal amino acids in Xsc was done by Edman degradation under contract by the sequencing facility of the Fachhochschule Bingen, Germany (http://zpa.fh bingen.de). Values of apparent $K_{\mathrm{m}}\left(K_{\mathrm{m}}^{\mathrm{app}}\right)$ were derived by hyperbolic curve fitting as cited elsewhere (Ruff et al., 2003). The identity of sulfoacetaldehyde as the product of $\mathrm{TDH}$ and of IDH was confirmed by matrix assisted, laser desorption ionization time of flight mass spectrometry (MALDI TOF MS) which was done under contract at the University of Saarbrücken, Germany: the negative ion mode was used for the underivatized alde hyde and, after reaction with hydroxylamine, for the corresponding oxime (Tholey et al., 2002).

Amplification, nucleotide sequencing and sequence analysis of genes. PCR was done in $20 \mu \mathrm{l}$ reaction mixtures with whole cells of $P$. denitrificans NKNIS (or of strains of $P$. pantotrophus or other organ isms) as template, with Taq polymerase (Genaxxon Bioscience) in Long Template Expand PCR buffer P2 or P3 (Roche Diagnostics). Primers were purchased from Hermann GbR Synthetische Biomoleküle or biomers.net $\mathrm{GmbH}$. The key primer pair, used in the initial amplifica tion of the $x s c$ gene (subgroup 3 ), was xsc3 $\mathrm{f}\left(5^{\prime}\right.$ TGGGCTACAACG GYTCGAA $3^{\prime}$ ) with xsc3 r (5' GCSCCCCACTGGTAGTTGCG $\left.3^{\prime}\right)$. Consensus primers to amplify a $1 \mathrm{~kb}$ fragment of the $\operatorname{tau} Y$ gene were tauYcons $f\left(5^{\prime}\right.$ TAYGCGCCGACCTACTGGRYCG $\left.3^{\prime}\right)$ and tauYcons $r$ (5' CGCGGCATCATGTCGTGGCTSAC 3').

Nucleotide sequences were determined by cycle sequencing and primer walking using the ABI BigDye Terminator v3.1 Cycle Sequencing Kit. The ABI DNA sequencers were operated by GATC GmbH. Sequence analysis was done using the DNASTAR LASERGENE program package version 5.5. The NCBI BLAST programs were used to search for similarities to the obtained sequences (Altschul et al., 1997). Multiple sequence alignments were carried out using the CLUSTALW method with a pairwise progress of MEGALIGN from the DNASTAR program package. Searches for motifs were done using the algorithms of the 
Profile Scan Server (http://hits.isb sib.ch/cgi bin/PFSCAN) or the Neural Network Promoter Prediction tool (NNPP; http://searchlauncher.bcm. tmc.edu/seq search/gene search.html) (Reese et al., 1996).

Sequence data on Burkholderia sp. strain LB400, Ral. eutropha JMP134, Rho. sphaeroides 2.4.1 and Rhodopseudomonas palustris CGA009 were produced by the US Department of Energy Joint Genome Institute (http://www.jgi.doe.gov/JGI microbial/html/index.html). Preliminary sequence data on Silicibacter pomeroyi DSS 3, and information on funding the project, were obtained from The Institute for Genomic Research (http://www.tigr.org). Sequence data on Rhodococcus sp. strain RHA1 were generated by the Microbial Envirogenomics Team at the University of British Columbia (http://www.bcgsc.bc.ca/cgi bin/ rhodococcus/blast rha1.pl). The accession number for clone P1023 in the Leishmania major genome project is AC091510. Sequence data for Rhodobacter capsulatus SB1003 are available from PEDANT (http://pedant.gsf.de).

\section{RESULTS}

\section{The putative taurine locus on the chromosomes of Rho. sphaeroides and $\boldsymbol{P}$. denitrificans}

We have partially reannotated the putative taurine locus of Sin. meliloti (SMb21525-SMb21532) for our own convenience (Fig. 1b) and expanded the annotation to cover the analogous putative taurine locus on the chromosome of Rho. sphaeroides (Rsph2616-Rsph2608) (Fig. 1b): the major difference between the two loci is that the tauABC genes in Sin. meliloti are replaced by tauKLM (encoding a putative TRAP transporter) in Rho. sphaeroides (Fig. 1b) (Table 1). We thus postulated for Rho. sphaeroides an inducible, taurine-degradative pathway involving a regulator protein TauR, TRAP transporter TauKLM, TDH (hypothetically TauXY), Xsc, a hypothetical protein (TauZ) and Pta, and we wondered whether this was widespread in Rhodobacteraceae.
PCR primers from each gene common to the $\mathrm{SMb}$ and Rsph loci were derived and tested in pairs with, as template DNA, whole cells of $P$. denitrificans NKNIS or of strains of $P$. pantotrophus. The amplified fragments from each organism supported the presence of an $x s c$ gene (primer pair xsc3-f and xsc3-r), but only in P. denitrificans were we immediately able to generate contiguous sequence (about $10 \mathrm{kbp}$; Fig. 1b) which represented the whole gene cluster. The cluster tauRKLMXY-xsc-tauZ-pta corresponded to that found in Rho. sphaeroides and the two DNA sequences shared $80 \%$ identity. An inducible degradative pathway involving a TRAP transporter, TDH, Xsc and Pta was thus inferred and P. denitrificans NKNIS was chosen for biochemical work.

Expansion of the initial sequence ( $x s c$ gene) in the taurine locus in both strains of $P$. pantotrophus initially indicated the same nine-gene cluster as in Rho. sphaeroides (Fig. 1b, Table 1). However, when the transport genes were sequenced, tau $A B C$ like genes were found (Fig. 1b). P. pantotrophus thus appears to encode an $\mathrm{ABC}$ transporter for taurine, as postulated for Sin. meliloti (Fig. 1b). The high levels of identity between the corresponding genes in Rho. sphaeroides and P. denitrificans (Table 1) and the widespread recurrence of the putative regulator in P. pantotrophus strains NKNCYSA and DSM 65 (Fig. 1b) and in other organisms (see below) allowed use of the TauR from Rho. sphaeroides to predict the class of regulator involved: it is a subgroup of the GntR family (see Rigali et al., 2002).

\section{Growth of $\boldsymbol{P}$. denitrificans with taurine, isethionate or acetate}

$P$. denitrificans NKNIS grew with taurine as sole source of carbon and energy under aerobic conditions with a specific

Table 1. Analysis of the gene cluster inferred to encode taurine dissimilation in Rho. sphaeroides 2.4 .1 compared with that in $P$. denitrificans NKNIS

\begin{tabular}{|c|c|c|c|c|c|}
\hline Gene number & $\begin{array}{l}\text { Length in Rsph } \\
\text { (NKNIS) [bp] }\end{array}$ & $\begin{array}{l}\text { Identity with } \\
\text { gene in strain } \\
\text { NKNIS (\%) }\end{array}$ & $\begin{array}{c}\text { Identity with } \\
\text { nearest homologue } \\
\text { in database }(\%)\end{array}$ & $\begin{array}{l}\text { Function of product in } \\
\text { domain search }\end{array}$ & $\begin{array}{l}\text { Function in Rsph } \\
\text { and strain NKNIS }\end{array}$ \\
\hline Rsph2615 (tauK) & $1056(1011)$ & 80 & 33, Bh2673 & $\begin{array}{l}\text { TRAP periplasmic binding } \\
\text { protein }\end{array}$ & $\begin{array}{l}\text { TRAP periplasmic binding } \\
\text { protein (putative) }\end{array}$ \\
\hline Rsph2613 (tauM) & $1341(1341)$ & 83 & 45, Bh2671 & $\begin{array}{l}\text { TRAP large permease } \\
\text { component }\end{array}$ & $\begin{array}{l}\text { TRAP large permease } \\
\text { component (putative) }\end{array}$ \\
\hline Rsph2612 (tauX) & $396(420)$ & $81^{\star}$ & $61, \mathrm{SMb} 21670$ & None & TDH subunit (putative) \\
\hline Rsph2611 (tauY) & $1389(1392)$ & $81^{\star}$ & 66, SMb21529 & D Amino acid oxidase & TDH subunit (putative) \\
\hline
\end{tabular}

${ }^{\star}$ The level of identity to sequence in strains NKNCYSA and strain DSM 65 was usually $>90 \%$. 
rate of $0 \cdot 19 \mathrm{~h}{ }^{1}$. The molar growth yield was $7 \mathrm{~g}$ protein $(\mathrm{mol} \mathrm{C}){ }^{1}$, and $0.7 \mathrm{~mol} \mathrm{NH}_{4}^{+}$(mol taurine) ${ }^{1}$ and $0.93 \mathrm{~mol}$ sulfate (mol taurine) ${ }^{1}$ were excreted into the growth medium. Sulfite ion (up to $1.6 \mathrm{mM}$ ) was detected in the growth medium. These data correspond to quantitative dissimilation of taurine at a specific degradation rate of 3.8 mkat ( $\mathrm{kg}$ protein) ${ }^{1}$, with assimilation of the anticipated amounts of ammonium and sulfate ions. The release of about $15 \%$ of the sulfonate sulfur as sulfite implied low levels of any sulfite dehydrogenase.

Corresponding experiments with isethionate gave a specific growth rate of $0 \cdot 18 \mathrm{~h}{ }^{1}$, a molar growth yield of $7 \mathrm{~g}$ protein (mol C) ${ }^{1}$ and excretion of $0.92 \mathrm{~mol}$ sulfate (mol isethionate) ${ }^{1}$; some $10 \%$ of the sulfonate group was recovered transiently as sulfite. Here again we conclude quantitative substrate utilization at 3.8 mkat ( $\mathrm{kg}$ protein) ${ }^{1}$.

Extracts of strain NKNIS grown with acetate contained no detectable TDH, IDH, Xsc or sulfite dehydrogenase, but they did contain traces of Pta (Table 2). Extracts of taurinegrown cells contained TDH, Xsc and high levels of Pta, but no IDH was detected (Table 2). The isethionate-grown cells, in contrast, contained IDH, Xsc and high levels of Pta, but no TDH (or sulfite dehydrogenase) was detected. The specific activities of Xsc [2-4 mkat (kg protein) ${ }^{1}$; Table 2] were in the range calculated to be needed for growth of strain NKNIS [3.8 mkat (kg protein) ${ }^{1}$; see above], as was Pta, so we presume that we have assayed enzymes involved in the degradation of taurine and isethionate. The specific activity of TDH [7.3 mkat ( $\mathrm{kg}$ protein) ${ }^{1}$; Table 2] was also sufficient to explain the growth rate, whereas the level of IDH was apparently somewhat too low (Table 2). Cytochrome $c$, identified from a redox difference spectrum with maxima at 425, 522 and $551 \mathrm{~nm}$ (Voet et al., 1999), was detected at 5-20 $\mathrm{g}$ (kg protein) ${ }^{1}$ in extracts of taurine- and acetategrown cells: this later led us to test an analogous protein as electron acceptor in assays of TDH and IDH. As predicted from literature data in other organisms (Cook \& Denger,

Table 2. Specific activities of TDH, Xsc, Pta, IDH and sulfite dehydrogenase in extracts of cells of $P$. denitrificans NKNIS grown with different substrates

\begin{tabular}{|c|c|c|c|}
\hline \multirow[t]{2}{*}{ Enzyme } & \multicolumn{3}{|c|}{$\begin{array}{l}\text { Specific activity of enzymes in } \\
\text { extracts of cells grown with } \\
\text { the following carbon source } \\
{\left[\text { mkat (kg protein) }{ }^{1}\right]^{*}}\end{array}$} \\
\hline & Acetate & Taurine & Isethionate \\
\hline TDH & ND & $7 \cdot 3$ & ND \\
\hline Xsc & ND & $2 \cdot 1$ & $4 \cdot 2$ \\
\hline Pta & $0 \cdot 4$ & 10 & $13 \cdot 6$ \\
\hline IDH & ND & ND & $0 \cdot 6$ \\
\hline Sulfite dehydrogenase & ND & ND & ND \\
\hline
\end{tabular}

${ }^{\star} \mathrm{ND}$, Not detectable $\left[<0.005\right.$ mkat $\left(\mathrm{kg}\right.$ protein $\left.{ }^{1}\right]$.
2002), Xsc and Pta were induced during growth with each sulfonate substrate, whereas TDH (or IDH) was present solely during growth with taurine (or isethionate). Constitutive Tpa was detected, but with negligible activity $\left.[<0.01 \mathrm{mkat} \text { ( } \mathrm{kg} \text { protein })^{1}\right]$ which we attribute to the side reaction of another enzyme.

\section{The reactions catalysed by TDH, Xsc, Pta and IDH}

The routine assay of TDH involved the reduction of DCPIP which was not in itself specific. However, the reduction of DCPIP depended absolutely on the presence of taurine, and boiled extract was inactive. The apparent $K_{\mathrm{m}}$ value $\left(K_{\mathrm{m}}^{\mathrm{app}}\right)$ for DCPIP was about $50 \mu \mathrm{M}$. The $K_{\mathrm{m}}^{\text {app }}$ value for taurine was about $7 \mathrm{mM}$. The reaction mixture initially contained no sulfoacetaldehyde, but after exhaustion of the DCPIP, sulfoacetaldehyde was tentatively identified by co-chromatography (HPLC) of the azine derivative with the azine derivative of authentic material. The identification was confirmed by negative-ion MALDI-TOF-MS where the same base peak, $m / z=123$ ( $M$ 1 $)$, was observed, as with authentic material. The release of ammonium ion during the reaction was also detected (Berthelot reaction) (cf. Fig. 1); no ammonium ion was detected in the absence of taurine. The preliminary identification of ammonium ion was confirmed by the specific reaction with glutamate dehydrogenase. We presume the stoichiometry of TDH to be $1: 1: 1$ (taurine/sulfoacetaldehyde/ammonium ion). About $3 \mathrm{mM}$ sulfoacetaldehyde was indeed formed during the disappearance of about $3 \mathrm{mM}$ taurine, but ammonium ion could not be measured in the same reaction because of interference from DCPIP and taurine. When we compared the amount of sulfoacetaldehyde formed (e.g. $3 \mathrm{mM}$ ) with the amount of DCPIP apparently reduced $(0.5 \mathrm{mM})$ in a reaction mixture, we presumed that spontaneous reoxidation of DCPIP occurred during the reaction.

The following compounds were tested as the potential electron acceptor for the oxidation of taurine: FAD, FMN, riboflavin, PQQ, 1,4-naphthoquinone, ubiquinone, menadione, $\mathrm{K}_{3} \mathrm{Fe}(\mathrm{CN})_{6}$ and cytochrome $c$. Only cytochrome $c$ functioned as an acceptor, but although the reaction rate was increased by a factor of about 15 , the value for $K_{\mathrm{m}}^{\text {app }}$ was scarcely altered $(6 \cdot 2 \mathrm{mM})$. TDH was detected as an inducible enzyme in Sin. meliloti $\mathrm{Rm} 1021$ [0.6 mkat ( $\mathrm{kg}$ protein) ${ }^{1}$ ], the organism in which the tauXY genes were first suspected to encode TDH, in P. pantotrophus NKNCYSA [0.7 mkat ( $\mathrm{kg}$ protein) $\left.{ }^{1}\right]$ where the tauXY genes are found (Fig. 1) and in Burkholderia sp. strain LB400 $\left[0 \cdot 2\right.$ mkat (kg protein) $\left.{ }^{1}\right]$, where the tauXY-like genes (Bcep5174-5173) are in close proximity to the xsc gene (Bcep5167) (Fig. 1b). A. defragrans NKNTAU, in which Tpa is active (Ruff et al., 2003), contained neither measurable TDH nor a tauY-like fragment detectable by PCR with the appropriate consensus primers.

TDH was discovered in Achromobacter xylosoxidans NCIMB 10751 (Kondo et al., 1971, 1973), but the difficulty we experience in growing the organism with taurine (Ruff et al., 2003) 
meant that we could not measure the activity directly. We could, however, amplify a DNA fragment $(1 \mathrm{~kb})$ from strain NCIMB 10751 with the consensus primer pair designed to detect tau $Y$ genes. The fragment showed $67 \%$ identity to the corresponding portion of the tauY gene in Burkholderia sp. strain LB400 and $70 \%$ identity at the level of the derived amino acid sequence. Achromobacter sp. has been assigned, with scanty evidence, to a risk group which makes its legal transfer to other laboratories impracticable. Given the availability of more easily grown organisms that utilize taurine and isethionate (e.g. Burkholderia sp. strain LB400) and may be transported easily, and the pending complete genome sequence for strain LB400, it seems rational to make this bacterium the basis for comparisons.

Genes, like those attributed to taurine degradation in Burkholderia sp. strain LB400 (Fig. 1b), were found in Ral. eutropha JMP134 (Fig. 1b) and we confirmed our postulate that the latter organism could grow with taurine as sole source of carbon and energy for growth. Ralstonia sp. strain EDS1 dissimilates taurine (Denger \& Cook, 2001), so we postulated that this organism would also contain the tauY gene. The DNA fragment $(1 \mathrm{~kb})$ obtained with the consensus primer pair shared $67 \%$ sequence identity with the corresponding portion of the tauY-like gene in strain LB400. Comamonas sp. strain SFCD1, which dissimilates taurine, also contains a $1 \mathrm{~kb}$ DNA sequence with $67 \%$ identity to the tauY gene of strain LB400. There is a strong correlation between the $\operatorname{tau}(X) Y$ genes and the dissimilation of taurine.

The Xsc reaction in strain NKNIS depended absolutely on the presence of inorganic phosphate, and yielded acetyl phosphate and sulfite, as anticipated (Cook \& Denger, 2002). Simple rebuffering experiments showed the loss of $80 \%$ of activity in the absence of ThDP and of $20 \%$ in the absence of $\mathrm{Mg}^{2+}$ : we presume that both factors are required for activity, but that the rebuffering was not rigorous enough. The following values for $K_{\mathrm{m}}^{\mathrm{app}}$ were obtained: sulfoacetaldehyde, $2 \cdot 8 \mathrm{mM}$; phosphate, $2 \cdot 4 \mathrm{mM}$; ThDP, $3 \cdot 1 \mu \mathrm{M}$.

The assay of Pta, based on the formation of acetyl CoA, was positive, so the degradation of taurine yields the substrate for the Krebs and glyoxylate cycles, as foreseen in Fig. 1.

The assay of IDH was initially followed as the reduction of DCPIP. This reduction depended absolutely on the presence of isethionate, and boiled extract was inactive. The $K_{\mathrm{m}}^{\mathrm{app}}$ value for isethionate was about $1 \mathrm{mM}$. The reaction mixture initially contained no sulfoacetaldehyde, but after exhaustion of the DCPIP, sulfoacetaldehyde was tentatively identified by co-chromatography (HPLC) of the azine derivative with the azine derivative of authentic material. The identification was confirmed by MALDI-TOF-MS, both as the underivatized compound and as the oxime. We did not determine isethionate, so no data on stoichiometry are available. An inducible protein with a molecular mass of $62 \mathrm{kDa}$ under denaturing conditions was observed in crude extracts (Fig. 2, lane 3) and in the membrane fraction (Fig. 2, lane 9) of isethionate-grown cells. We then detected that cytochrome $c$ served as electron acceptor for IDH.

\section{Separation of Xsc and Pta}

A diluted soluble fraction of taurine-grown $P$. denitrificans NKNIS was loaded onto an anion exchange column. Two enzymes were analysed in the eluate, Xsc, which eluted at $140 \mathrm{mM}$ sodium sulfate, and Pta, which eluted at $110 \mathrm{mM}$ sodium sulfate (Fig. 3). The separation of Xsc was effectively a one-step purification (Fig. 2, lane 5; Table 3). The Pta fraction contained several proteins, the occurrence of only one of which was representative of the Pta activity in the fractions 43-47 and also corresponded in molecular mass $(33 \mathrm{kDa})$ to that derived from the pta gene in strain NKNIS. This protein was present in small amounts and Pta was not examined further.

Xsc from strain NKNIS was estimated to have a molecular mass of about $64 \mathrm{kDa}$ (Fig. 2, lane 5). Gel filtration chromatography (not shown) of the native protein on a calibrated column indicated a molecular mass of about $217 \mathrm{kDa}$, so, given a unique $\mathrm{N}$-terminal sequence (see below), a homomultimeric, possibly tetrameric, Xsc was assumed. The

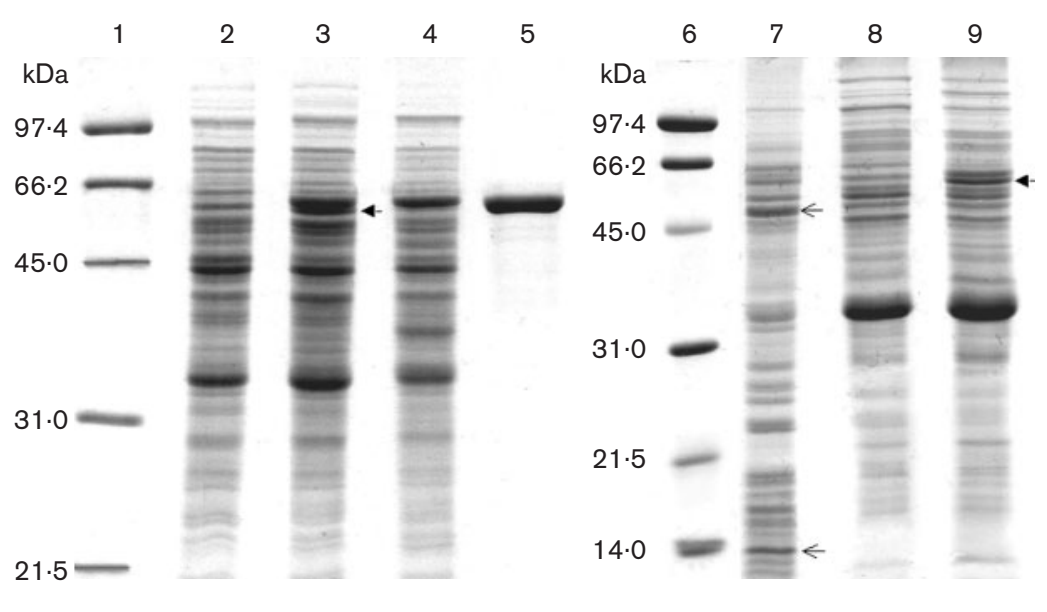

Fig. 2. Electropherograms (SDS-PAGE) of denatured proteins from crude extracts or membrane fractions of $P$. denitrificans NKNIS grown with different substrates, and of a fraction from a chromatographic separation of Xsc. Lanes: 1, 6, molecular mass markers; 2, crude extract of acetate-grown cells; 3 , crude extract of isethionate-grown cells; 4, crude extract of taurine-grown cells; 5, separated Xsc; 7, membrane fraction from taurine-grown cells; 8, membrane fraction from acetate-grown cells; 9, membrane fraction from isethionate-grown cells. Arrows mark the $62 \mathrm{kDa}$ protein tentatively attributed to IDH (lanes 3, 9) and the 50 and $14 \mathrm{kDa}$ bands tentatively attributed to TDH (lane 7). 


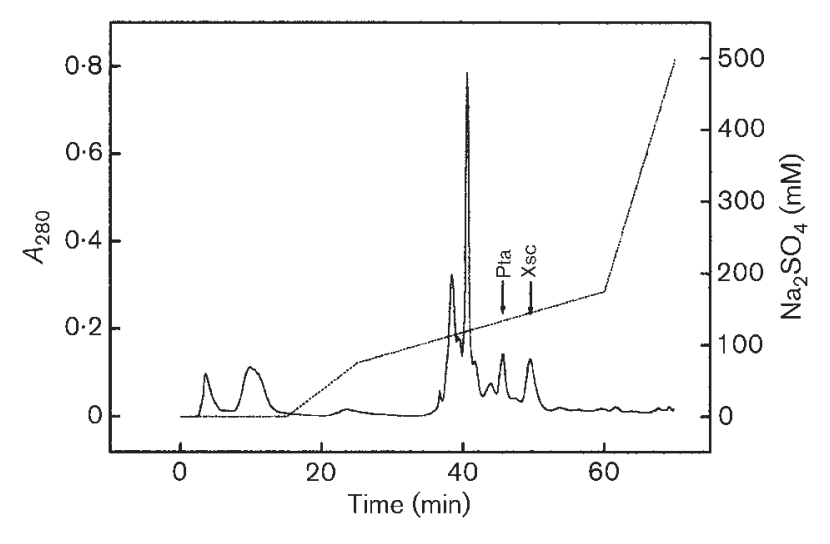

Fig. 3. The separation of soluble proteins in an extract from taurine-grown $P$. denitrificans NKNIS on an anion-exchange column and the elution of Xsc and Pta (arrows). About $50 \mathrm{mg}$ protein was loaded onto the column and a non-linear gradient of $\mathrm{Na}_{2} \mathrm{SO}_{4}$ (dotted line) was used to elute protein (solid line), which was detected at $A_{280}$.

$\mathrm{N}$-terminal amino acid sequence was determined to be MRMTTEES; there was no ambiguity, so all subunits were identical. This peptide was present in the deduced sequence of the putative $x s c$ gene and allowed the $x s c$ gene to be defined, because there were several possible start codons in the DNA sequence. The data thus confirm the identity of the $x s c$ gene and allowed the molecular mass of the protein to be derived as $64 \cdot 4 \mathrm{kDa}$, in agreement with the data from SDS-PAGE (Fig. 2, lane 5).

TDH from strain NKNIS was found exclusively in the particulate fraction [at 25 mkat (kg protein) ${ }^{1}$ ]. The membrane proteins of differently grown cells were examined, and inducible formation of two proteins (14 and $50 \mathrm{kDa}$ ) in membranes of taurine-grown cells was detected by SDSPAGE (Fig. 2, lane 7). We thus maintain the hypothesis that the gene products TauXY represent TDH.

\section{DISCUSSION}

Genomic sequence data from Sin. meliloti (Finan et al., 2001), together with biochemical data on Xsc in $A$. defragrans, allowed us to postulate a regulated degradative pathway for taurine in Sin. meliloti (Ruff et al., 2003). That, in turn, allowed a similar pathway to be proposed for Rho. sphaeroides (Cook \& Denger, 2002) (Fig. 1, Table 1). This paper shows that one cluster of nine genes is present in both Sin. meliloti and P. pantotrophus DSM 65 (Fig. 1) and that a similar cluster is found in both Rho. sphaeroides and $P$. denitrificans (Table 1). There was, thus, a biological system with which to test the hypotheses derived from data in silico. The confirmation that the hypothetical $x s c$ gene in $P$. denitrificans NKNIS does indeed encode Xsc infers that all $x s c$ genes in subgroup 3 encode this product, and this indicates that the gene clusters in both Sin. meliloti [SMb21525-SMb21532, where inducible TDH (see above), Xsc and Pta are known (Ruff et al., 2003)] and in Rho. sphaeroides [Rsph2616-2608, where catabolism of taurine has been observed (K. Denger, unpublished)] do encode the enzymes of taurine dissimilation.

The putative regulator, TauR, was suggested because the corresponding gene was adjacent to the then tentative taurine gene cluster in Sin. meliloti (Fig. 1b) (Ruff et al., 2003). A similar, putative regulator gene is found in all sequenced taurine utilizers (Fig. 4a), which represent $\alpha$ - and $\beta$ Proteobacteria and high-G $+\mathrm{C}$ Gram-positive bacteria. It is possible that TauR represents a new subgroup related to the ARO8 regulators (the result in all BLAST domain searches) of the MocR-group of GntR-like regulators, analogous to a recent finding in Anabaena (Lee et al., 2003). Analyses of mutants are now required to explore the role and function of TauR.

Little is known about the transport of sulfonates in catabolic pathways, whereas ABC transporters are widespread in scavenging systems associated with sulfate starvation (Kertesz, 2001; Cook \& Denger, 2002). We suspect an ABC transporter for taurine catabolism in the strains of $P$. pantotrophus (Fig. 1b), in concurrence with that inferred for taurine transport in Sin. meliloti (Fig. 1b) (Ruff et al., 2003) and with the ABC transporter for methanesulfonate (de Marco et al., 1999; Kertesz, 2001). The sequences of the genes encoding putative TauABC transporters in Sin. meliloti, Burkholderia sp. strain LB400, L. major and Ral. eutropha were examined in dendrograms (not shown) and they group very close to the corresponding genes encoding TauA (or TauB or TauC) in Escherichia coli and at a distance from the corresponding component of the TRAP transporters. In contrast to $\mathrm{ABC}$ transporters in e.g. Sin. meliloti, we suggest that TRAP transporters are involved in the transport of taurine in P. denitrificans and Rho. sphaeroides (Table 1). Here again, the generation of mutants is needed, as are assays

Table 3. Purification of Xsc

\begin{tabular}{|lcccccc|}
\hline Fraction & $\begin{array}{c}\text { Volume } \\
(\mathbf{m l})\end{array}$ & $\begin{array}{c}\text { Total } \\
\text { protein }(\mathbf{m g})\end{array}$ & $\begin{array}{c}\text { Total activity } \\
(\boldsymbol{\mu} \mathbf{k} \text { at })\end{array}$ & $\begin{array}{c}\text { Specific activity } \\
{[\mathbf{m k a t}(\mathbf{k g} \text { protein) })}\end{array}$ & $\begin{array}{c}\text { 1 }] \\
\text { [ furification } \\
\text { factor }(\mathbf{f o l d})\end{array}$ & $\begin{array}{c}\text { Yield } \\
(\%)\end{array}$ \\
\hline Crude extract & $3 \cdot 0$ & 149 & $0 \cdot 24$ & $1 \cdot 6$ & 1 & 100 \\
Soluble fraction & $2 \cdot 4$ & 110 & $0 \cdot 24$ & $2 \cdot 1$ & $1 \cdot 3$ & 97 \\
Dilution & $6 \cdot 0$ & 108 & $0 \cdot 23$ & $2 \cdot 2$ & $1 \cdot 3$ & 95 \\
Mono Q eluate & $4 \cdot 8$ & $2 \cdot 4$ & $0 \cdot 04$ & $16 \cdot 5$ & 10 & 16 \\
\hline
\end{tabular}




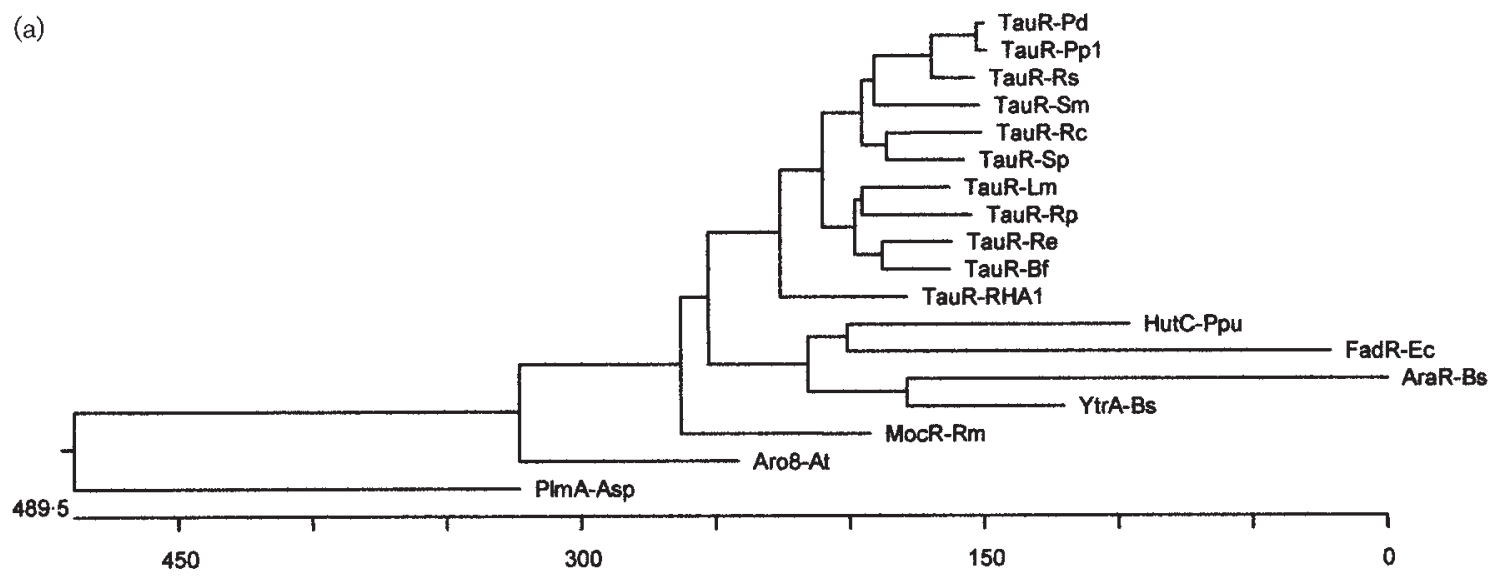

(b)

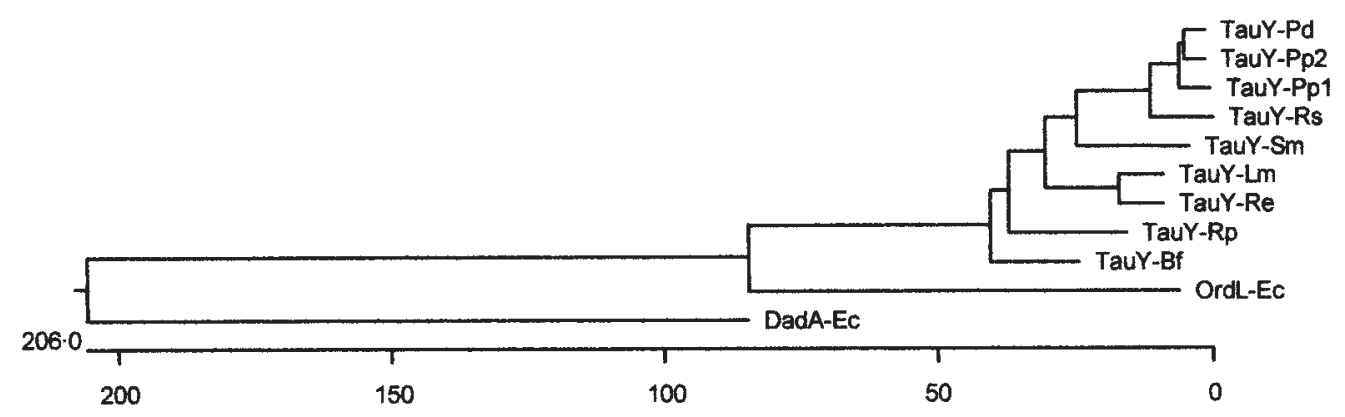

Amino acid substitutions

Fig. 4. Dendrograms with TauR in the GntR family of regulators, and TauY sequences with the best hit (OrdL) in BLAST searches and in domain searches (DadA). The deduced amino acid sequences of the gene products and the relevant comparisons were processed in CLUSTALW software to generate the dendrograms. The abbreviation for each protein is followed by an abbreviation for its source: At, Agrobacterium tumefaciens; Bf, Burkholderia sp. strain LB400; Bs, Bacillus subtilis; Ec, E. coli K-12; Lm, contaminant DNA (clone P1023) in the L. major genome sequence project; Pd, P. denitrificans NKNIS; Pp1, P. pantotrophus NKNCYSA; Pp2, P. pantotrophus DSM 65; Ppu, Pseudomonas putida; Rc, Rho. capsulatus SB1003; Re, Ral. eutropha JMP134; RHA1, Rhodococcus sp. strain RHA1; Rp, Rps. palustris CGA009; Rs, Rho. sphaeroides 2.4.1; Sm, Sin. meliloti Rm1021; Sp, Sil. pomeroyi DSS-3. The accession numbers of sequences used as outgroups or comparisons are: AraR, P96711; Aro8, AAL42844; DadA, AAC74273; FadR, P09371; HutC, P22773; MocR, P49309; OrdL, AAC74383; PImA, AAO92602; YtrA, CAB15024.

of transport, to test these hypotheses. The TRAP transporter presumably represents a new member of the TC 2.A.56.1.family (Saier, 1999), whereas the ABC transporter is a tentative member of TC 3.A.1.17.1 (see Kertesz, 2001).

There are reasonable data to support a mass balance for the oxidative deamination of taurine to sulfoacetaldehyde by $\mathrm{TDH}$, but although difficulties with DCPIP have left an incomplete picture of the overall stoichiometry of the reaction, there is no reason to doubt the representation in Fig. 1. Our biochemical approaches to purify TDH, where proteins of 14 and $50 \mathrm{kDa}$ were observed (Fig. 2), all support the hypothesis that the enzyme is encoded by tauXY, which potentially encode proteins of 15 and $51 \mathrm{kDa}$, respectively, but other possibilities have not been excluded. All tested organisms with tauXY-like genes express $\mathrm{TDH}$, whereas organisms with no apparent homologue of tauXY [A. defragrans (see above) and Rhodococcus sp. strain RHA1] and an active Tpa, do not (K. Denger, unpublished). We infer that the gene products of tauXY contribute to the function of TDH and we anticipate that heterologous expression of the genes will allow the question to be answered conclusively. The TDH described or mentioned previously (Fellman et al., 1980; Kondo \& Ishimoto, 1987) is a particulate system for which no molecular description is available, presumably because the respiratory chain was used for the enzyme assay in an oxygen electrode. This poor definition is reflected in enzyme nomenclature, where the accession number is EC 1.4.99.2. The recognition that cytochrome $c$ is the natural electron acceptor potentially allows the enzyme to be reclassified as taurine-ferricytochrome $c$ reductase EC 1.4.2.-, a group which currently has only one entry (Sanders et al., 1972).

Analyses in Prosite indicated significant similarity of TauY 
binding motifs to the FAD-linked amino acid oxidases only, as represented by DadA (see Fig. 4b). The addition of FAD had no effect on activity. The sequence motifs of TauXY give no reason to suspect that these are membrane proteins, but TDH is found in the membrane fraction. BLASTP searches with the sequence of TauY yield, after a set of TauXY homologues, a large number of TauY-like hypothetical proteins. Those tauY-like genes, which have an adjacent tauX gene, fall into one group (Fig. 4b) which is independent of the phylogeny of the organisms concerned. The other, larger group of TauY-like putative proteins has no known function, but one has been named in E. coli, ordL (Jovanovic \& Model, 1997). OrdL falls into a separate group from TauY and both are distinctly separate from DadA (Fig. 4b).

The Xsc purified here is encoded by a subgroup-3 xsc gene. The enzyme has many similarities to those in subgroup 1, namely the relatively high $K_{\mathrm{m}}^{\mathrm{app}}$ value for sulfoacetaldehyde (mM value) and the requirement for ThDP in the reaction mixture, in contrast to the subgroup- 2 enzyme, with its higher affinity for sulfoacetaldehyde and tightly bound ThDP (Denger et al., 2001; Ruff et al., 2003). The newly characterized Xsc from the subgroup-3 genes is thus not biochemically different from the Xscs of subgroup 1 . As observed in many organisms (Ruff et al., 2003), Xsc is strongly induced in taurine- (and isethionate-) grown cells of strain NKNIS (Fig. 2), which is in agreement with the 10-fold purification to yield an essentially homogeneous protein (Fig. 3, Fig. 2). This is the first Xsc to be isolated with the initiatory M retained in the protein, but this observation does fit the consensus for the E. coli aminopeptidase, where the M followed by $\mathrm{R}$ or $\mathrm{K}$ is not cleaved (Ben-Bassat et al., 1987). Indeed, xsc subgroup 3 is the only known subgroup to have a conserved $\mathrm{N}$-terminal sequence, so presumably the initiatory $\mathrm{M}$ is never cleaved. This conserved sequence results in the thiamin-phosphate-activating glutamate in the biochemical reaction (Bar-Ilan et al., 2001) always being E49. The expansion of xsc subgroup 3 from three to eight members has not altered the general structure of the dendrogram generated earlier (see Ruff et al., 2003) to illustrate the three subgroups, or required any further alteration of the consensus pattern for the ThDP-binding site (see Ruff et al., 2003). Little work has been put into the Pta enzymes in the taurine pathway, except to confirm their presence, but there is no evidence that they fall into different subgroups (dendrogram not shown).

This discussion of the genes and gene products in the taurine pathway tends to imply a common regulation of expression of the eight genes presumed to be under the control of TauR, and this is a fair assumption during growth with taurine, with the need for transport, as well as the expression of TDH (presumably TauXY), Xsc and Pta (Table 2). When the cells utilize isethionate, however, the same Xsc seems to be present (Fig. 2), with Pta, though there is no TDH (presumably TauXY), but there is expression of IDH (Table 2). The intergenic space between tauY and $x s c$ is only $12 \mathrm{bp}$, so there must be an unusual regulatory system to allow expression of a downstream region, when the upstream genes are not expressed.

The present work with IDH in strain NKNIS would appear to be the first direct assay of the enzyme since its discovery in the particulate fraction of strain NCIMB 10751 in 1977 (Kondo et al., 1977). IDH in strain NKNIS is also in the particulate fraction, and we suspect that a $62 \mathrm{kDa}$ protein may catalyse the reaction (Fig. 2). The rules of enzyme nomenclature enable a cytochrome $c$-dependent alcohol dehydrogenase to be attributed to EC 1.1.2.-, which has relatively few entries, as yet. Given an inducible IDH (Table 3), we infer the presence of an isethionate regulator, a transport system and IDH, presumably encoded in a cluster.

P. denitrificans NKNIS is one of the organisms which excretes some sulfite during growth with a sulfonate substrate (Fig. 1a). We could not detect sulfite dehydrogenase (oxidase), so we presume that sulfite is subject to spontaneous oxidation to sulfate. It is unclear where this oxidation occurs, possibly in part inside the cell, but a portion is certainly oxidized extracellularly. It is thus unclear whether sulfite or sulfate, or both, is subject to export, and what mechanisms are used for this export and to sense the need for it. $P$. pantotrophus NKNCYSA expresses a sulfite dehydrogenase and excretes only sulfate (Rein, 1999). Sin. meliloti potentially encodes at least one sulfite dehydrogenase (SMa2103) and one sulfite oxidase (SMc04049), whereas Rho. sphaeroides appears to encode none, so we anticipate release of sulfite into the medium when Rho. sphaeroides utilizes taurine, but not when Sin. meliloti utilizes it. When the presumed requirement for the export of sulfate/sulfite to maintain a constant ionic strength within the cell is valid, another regulatory system and an export system must be required for the ammonium ion (or for the neutral species) (Fig. 1). Ammonium/methylammonium transport (Amt) proteins (e.g. Meier-Wagner et al., 2001) may fill the latter role.

Degradation of taurine, in particular, is a very complex system with many unresolved questions which could well yield to analyses by gene arrays in a sequenced organism such as Sin. meliloti or Rho. sphaeroides.

\section{ACKNOWLEDGEMENTS}

We are grateful to participants in an advanced practical class and an exchange programme for data: Michael Weitnauer for work on $\mathrm{TDH}$ and IDH, and Hagai Liviatan and Tobias Eltze for sequence data. B. González (P. Universidad Católica de Chile; Ral. eutropha), C. Harwood (University of Iowa; Rps. palustris), R. Haselkorn (University of Chicago, Rho. capsulatus), S. Kaplan (University of Texas; Rho. sphaeroides), W. W. Mohn (University of British Columbia; Rhodococcus sp.), M. A. Moran (University of Georgia; Sil. pomeroyi) and J. Tiedje (Michigan State University; Burkholderia sp.) and the contact persons of the Microbial Envirogenomics Team at the University of BC, and at DOE and TIGR kindly acknowledged and approved a late draft of this paper with information on our suggested annotation of genes in genome sequencing projects in progress. Our research was funded by the University of Konstanz. 


\section{REFERENCES}

Altschul, S. F., Madden, T. L., Schäffer, A. A., Zhang, J., Zhang, Z., Miller, W. \& Lipman, D. J. (1997). Gapped BLAST and PSI BLAST: a new generation of protein database search programs. Nucleic Acids Res 25, 33893402.

Bar-Ilan, A., Balan, V., Tittmann, K., Golbik, R., Vyazmensky, M., Hubner, G., Barak, Z. \& Chipman, D. M. (2001). Binding and activation of thiamin diphosphate in acetohydroxyacid synthase. Biochemistry 40, 1194611954.

Ben-Bassat, A., Bauer, K., Chang, S. Y., Myambo, K., Boosman, A. \& Chang, S. (1987). Processing of the initiation methionine from proteins: properties of the Escherichia coli methionine aminopepti dase and its gene structure. J Bacteriol 169, 751757.

Bergmeyer, H. U. (1983). Determination of metabolite concentrations with end point methods. In Methods of Enzymic Analysis, vol. 1, pp. 163 181. Edited by H. U. Bergmeyer. Weinheim: Verlag Chemie.

Bergmeyer, H. U., GraßI, M. \& Walter, E.-M. (1983). Phospho transacetylase. In Methods of Enzymatic Analysis, vol. 2, pp. 295296. Edited by H. U. Bergmeyer. Weinheim: Verlag Chemie.

Chance, B. \& Williams, G. R. (1955). Respiratory enzymes in oxidative phosphorylation. II. Difference spectra. J Biol Chem 217, 395407.

Cook, A. M. \& Denger, K. (2002). Dissimilation of the $\mathrm{C}_{2}$ sulfonates. Arch Microbiol 179, 16.

Cunningham, C., Tipton, K. F. \& Dixon, H. B. F. (1998). Conversion of taurine into $N$ chlorotaurine (taurine chloramine) and sulpho acetaldehyde in response to oxidative stress. Biochem J 330, 939945.

de Marco, P., Moradas-Ferreira, P., Higgins, T. P., McDonald, I., Kenna, E. M. \& Murrell, J. C. (1999). Molecular analysis of a novel methanesulfonic acid monooxygenase from the methylotroph Methylosulfonomonas methylovora. J Bacteriol 181, 22442251.

Denger, K. \& Cook, A. M. (2001). Ethanedisulfonate is degraded via sulfoacetaldehyde in Ralstonia sp. strain EDS1. Arch Microbiol 176, 8995.

Denger, K., Laue, H. \& Cook, A. M. (1997). Anaerobic taurine oxidation: a novel reaction by a nitrate reducing Alcaligenes sp. Microbiology 143, 19191924.

Denger, K., Ruff, J., Rein, U. \& Cook, A. M. (2001). Sulfoacetaldehyde sulfo lyase [EC 4.4.1.12] from Desulfonispora thiosulfatigenes: pur ification, properties and primary structure. Biochem J 357, 581586.

Ehrmann, M., Ehrle, R., Hofmann, E., Boos, W. \& Schlosser, A. (1998). The ABC maltose transporter. Mol Microbiol 29, 685694.

Ensley, B. D., Gibson, D. T. \& Laborde, A. L. (1982). Oxidation of naphthalene by a multicomponent enzyme system from Pseudo monas sp. strain NCIB 9816. J Bacteriol 149, 948954.

Fellman, J. H., Roth, E. S., Avedovech, N. A. \& McCarthy, K. D. (1980). The metabolism of taurine to isethionate. Arch Biochem Biophys 204, 560567.

Finan, T. M., Weidner, S., Wong, K. \& 9 other authors (2001). The complete sequence of the $1,683 \mathrm{~kb}$ pSymB megaplasmid from the $\mathrm{N}_{2}$ fixing endosymbiont Sinorhizobium meliloti. Proc Natl Acad Sci U S A 98, 98899894.

Gesellschalt Deutscher Chemiker (1996). German Standard Methods for the Laboratory Examination of Water, Waste Water and Sludge. Weinheim: VCH.

Huxtable, R. J. (1992). Physiological actions of taurine. Physiol Rev 72, 101163.

Jones, K. M. (1979). Artificial substrates and biochemical reagents. In Data for Biochemical Research, pp. 436 465. Edited by R. M. C. Dawson, D. C. Elliott, W. H. Elliott \& K. M. Jones. Oxford. Oxford University Press.
Jovanovic, G. \& Model, P. (1997). The RIB element in the goa $G$ pspF intergenic region of Escherichia coli. J Bacteriol 179, 30953102.

Junker, F., Leisinger, T. \& Cook, A. M. (1994). 3 Sulphocatechol 2,3 dioxygenase and other dioxygenases (EC 1.13.11.2 and EC 1.14.12. ) in the degradative pathways of 2 aminobenzenesulphonic, benzene sulphonic and 4 toluenesulphonic acids in Alcaligenes sp. strain $\mathrm{O} 1$. Microbiology 140, 17131722.

Kappler, U. \& Dahl, C. (2001). Enzymology and molecular biology of prokaryotic sulfite oxidation. FEMS Microbiol Lett 203, 19.

Kelly, D. J. \& Thomas, G. H. (2001). The tripartite ATP independent periplasmic (TRAP) transporters of bacteria and archaea. FEMS Microbiol Rev 25, 405424.

Kertesz, M. A. (2000). Riding the sulfur cycle metabolism of sulfonates and sulfate esters in Gram negative bacteria. FEMS Microbiol Rev 24, 135175.

Kertesz, M. A. (2001). Bacterial transporters for sulfate and organosulfur compounds. Res Microbiol 152, 279290.

King, J. E. \& Quinn, J. P. (1997). Metabolism of sulfoacetate by environmental Aureobacterium sp. and Comamonas acidovorans isolates. Microbiology 143, 39073912.

King, J. E., Jaouhari, R. \& Quinn, J. P. (1997). The role of sulfoacetaldehyde sulfo lyase in the mineralization of isethionate by an environmental Acinetobacter isolate. Microbiology 143, 23392343.

Kondo, H. \& Ishimoto, M. (1987). Taurine dehydrogenase. Methods Enzymol 143, 496499.

Kondo, H., Anada, H., Ohsawa, K. \& Ishimoto, M. (1971). Formation of sulfoacetaldehyde from taurine in bacterial extracts. J Biochem 69, 621623.

Kondo, H., Kagotani, K., Oshima, M. \& Ishimoto, M. (1973). Purification and some properties of taurine dehydrogenase from a bacterium. J Biochem 73, 12691278.

Kondo, H., Niki, H., Takahashi, S. \& Ishimoto, M. (1977). Enzymatic oxidation of isethionate to sulfoacetaldehyde in bacterial extract. J Biochem 81, 19111916.

Kondo, H., Yazawa, M., Enami, M. \& Ishimoto, M. (1982). Sulfite production from benzenesulfonate by bacterial enzyme compared with taurine. Ganryu Aminosan 5, 237242.

Laemmli, U. K. (1970). Cleavage of structural proteins during the assembly of the head of bacteriophage T4. Nature 227, 680685.

Laue, H. \& Cook, A. M. (2000). Biochemical and molecular characterization of taurine: pyruvate transaminase from the anaerobe Bilophila wadsworthia. Eur J Biochem 267, 68416848.

Laue, H., Denger, K. \& Cook, A. M. (1997). Taurine reduction in anaerobic respiration of Bilophila wadsworthia RZATAU. Appl Environ Microbiol 63, 20162021.

Lee, M. H., Scherer, M., Rigali, S. \& Golden, J. W. (2003). PlmA, a new member of the GntR family, has plasmid maintenance functions in Anabaena sp. strain PCC 7120. J Bacteriol 185, 43154325.

Lie, T. L., Leadbetter, J. R. \& Leadbetter, E. R. (1998). Metabolism of sulfonic acids and other organosulfur compounds by sulfate reducing bacteria. Geomicrobiol J 15, 135149.

Meier-Wagner, J., Nolden, L., Jakoby, M., Siewe, R., Kramer, R. \& Burkovski, A. (2001). Multiplicity of ammonium uptake systems in Corynebacterium glutamicum: role of Amt and AmtB. Microbiology 147, 135143.

Mikosch, C., Denger, K., Schäfer, E.-M. \& Cook, A. M. (1999). Anaerobic oxidations of cysteate: degradation via a cysteate:2 oxoglutarate aminotransferase in Paracoccus pantotrophus. Micro biology 145, 11531160.

Racker, E. (1962). Fructose 6 phosphate phosphoketolase from Acetobacter xylinum. Methods Enzymol 5, 276280. 
Reese, M. G., Harris, N. L. \& Eeckman, F. H. (1996). Large scale sequencing specific neural networks for promoter and splice site recognition. In Biocomputing: Proceedings of the 1996 Pacific Symposium, pp. 737 738. Edited by L. Hunter \& T. E. Klein. Singapore: World Scientific Publishing.

Reichenbecher, W., Kelly, D. P. \& Murrell, J. C. (1999). Desulfonation of propanesulfonic acid by Comamonas acidovorans strain P53: evidence for an alkanesulfonate sulfonatase and an atypical sulfite dehydrogenase. Arch Microbiol 172, 387392.

Rein, U. (1999). Abbauweg(e) für Cysteat bei anaeroben Bakterien. Diplomarbeit, University of Konstanz, Konstanz, Germany.

Rigali, S., Derouaux, A., Giannotta, F. \& Dusart, J. (2002). Subdivision of the helix turn helix GntR family of bacterial regulators in the FadR, HutC, MocR, and YtrA subfamilies. J Biol Chem 277, 1250712515.

Ruff, J., Denger, K. \& Cook, A. M. (2003). Sulphoacetaldehyde acetyl transferase yields acetyl phosphate: purification from Alcaligenes defragrans and gene clusters in taurine degradation. Biochem J 369, 275285.
Saier, M. H., Jr (1999). A functional phylogenetic system for the classification of transport proteins. J Cell Biochem Suppl. 32 33, 8494.

Sanders, H. K., Becker, G. E. \& Nason, A. (1972). Glycine cytochrome $c$ reductase from Nitrobacter agilis. J Biol Chem 247, 20152025.

Sörbo, B. (1987). Sulfate: turbidimetric and nephelometric methods. Methods Enzymol 143, 36.

Stadtman, E. R. (1957). Preparation and assay of acetyl phosphate. Methods Enzymol 3, 228231.

Tholey, A., Wittmann, C., Kang, M. J., Bungert, D., Hollemeyer, K. \& Heinzle, E. (2002). Derivatization of small biomolecules for optimized matrix assisted laser desorption/ionization mass spectro metry. J Mass Spectrom 37, 963973.

Thurnheer, T., Köhler, T., Cook, A. M. \& Leisinger, T. (1986). Orthanilic acid and analogues as carbon sources for bacteria: growth physiology and enzymic desulphonation. J Gen Microbiol 132, 12151220.

Voet, D., Voet, J. G. \& Pratt, C. W. (1999). Fundamentals of Biochemistry. New York: Wiley. 